\title{
A CONTROLADORIA E O CAPITAL INTELECTUAL: UM ESTUDO EMPÍRICO SOBRE SUA GESTÃO*
}

\author{
THE CONTROLLERSHIP AND THE INTELLECTUAL CAPITAL: \\ AN EMPIRICAL STUDY ON ITS MANAGEMENT
}

\author{
MARIA THEREZA POMPA ANTUNES \\ Professora Doutora do Curso de Ciências \\ Contábeis da Faculdade de Ciências \\ Econômicas, Contábeis e Administrativas da \\ Universidade Presbiteriana Mackenzie - SP \\ E-mail: mariathereza@mackenzie.com.br
}

\section{RESUMO}

Este estudo objetivou investigar a adequação do Sistema de Informações Contábeis Gerenciais de grandes empresas brasileiras à gestão do $\mathrm{Ca}$ pital Intelectual. Assumiu-se a Controladoria como a área na empresa mais adequada para identificar, avaliar e mensurar esses elementos e para disponibilizar as informações necessárias à gestão das empresas no atingimento de sua missão. A pesquisa do tipo exploratória está baseada em uma amostra composta por 30 gestores de grandes empresas brasileiras. A análise dos dados, tratados por meio do método qualitativo (Análise de Conteúdo), permitiu verificar que a grande maioria dos gestores realiza investimentos em elementos do Capital Intelectual e que atribuíram indicadores para avaliar esses investimentos, mas não de forma integrada que permita a quantificação correta dos valores investidos e a avaliação do retorno desses investimentos. Por outro lado, os gestores mostraram-se receptivos a aplicar um modelo de gestão para tal fim e consideraram a Controladoria como a área mais adequada para gerenciar esse modelo.

Palavras-chave: Capital Intelectual; Controladoria; Sistemas de Informações Contábeis Gerenciais.

\begin{abstract}
The purpose of this essay is to investigate through the Controlling Departments how the Management Information Systems in large Brazilian companies treat investments on Intellectual capital elements. It has been assumed that the Controlling Department is the companies' most adequate area to identify, evaluate and measure such elements, and to provide the managerial information required for the accomplishment of each company's mission. The exploratory research is based on a sample of 30 managers of large Brazilian companies. The qualitative analysis of the data collected (Contents Analysis) lead us to the conclusion that the great majority of managers invest on detecting Intellectual Capital elements and have tools to evaluate such investment, but not in an integrated manner that permits to correctly quantify the invested amounts and to evaluate the return on the investment. On the other hand, managers have been receptive to adopt a managerial model for that purpose, if available, and have considered the Controlling Department as the most adequate area to manage such model.
\end{abstract}

Keywords: Intellectual Capital; Controllership; Managerial Accounting Information System. 


\section{INTRODUÇÃO}

Verifica-se que, nas últimas décadas vieram gradativamente ocorrendo mudanças na sociedade que ora culminam num processo de globalização mundial, com rápido avanço das tecnologias de produção, informática e de telecomunicação, assim como em outras transformações que sugerem novas formas de percepção e interpretação da sociedade como um todo.

Esse período de gradativas mudanças na economia mundial é apontado por muitos estudiosos do assunto como o período de transição de uma Sociedade Industrial para uma Sociedade do Conhecimento, pois aos demais recursos existentes - terra, capital e trabalho - junta-se o conhecimento (DRUCKER, 1993; SVEIBY, 1998; STEWART, 1994; 1998 e 2001).

Para as organizações empresariais, a aplicação do recurso do conhecimento, juntamente com as tecnologias disponíveis, produz benefícios intangíveis denominados Capital Intelectual (BROOKING, 1996). O aparecimento desse conceito conduz à necessidade de aplicação de novas estratégias, de uma nova filosofia de administração e de novas formas de avaliação do valor da empresa que contemplem o recurso do conhecimento.

Diante da expansão acelerada do conhecimento dentro das organizações é de se questionar o papel da Contabilidade dentro dessa realidade, principalmente das implicações da mensuração dos elementos intangíveis e, conseqüentemente, do $\mathrm{Ca}$ pital Intelectual.

A função que se atribui à Contabilidade é a de provedora de informações aos seus usuários que permitam julgamentos, decisões, controle, avaliações ou apenas conhecimento. De certo, "a Contabilidade veio se destacando ao longo dos séculos, por ser o principal sistema de informações das entidades (...)", conforme afirma ludícibus (1994, p.7).

Assumindo-se esse como o objetivo maior da Contabilidade, ele é alcançado por meio do estudo, avaliação, registro e controle do patrimônio e das mutações que nele ocorrem e na forma de relatórios, pareceres, demonstrações, quadros comparativos etc. são divulgados os resultados obtidos e a situação econômico-financeira das organizações.

Entretanto, nos últimos anos, a Contabilidade vem recebendo sérias críticas quanto a sua eficácia no reconhecimento dos elementos intangíveis, segundo se pode verificar em Edvinsson e Malone (1998); Kaplan e Norton (1997), Sveiby (1998), Boulton et al. (2000), Lev (2001, 2003 e 2004), dentre outros, que chegam a pôr em dúvida se a Contabilidade tem cumprido, satisfatoriamente, a sua missão. Esses autores, também, atribuem o não reconheci- mento e evidenciação desses elementos à discrepância que apresentam o valor contábil e o valor de mercado das ações de algumas empresas.

Por outro lado, é sabido que os Princípios Fundamentais de Contabilidade, mais as normas que balizam o registro dos fenômenos que afetam o patrimônio das entidades, impedem que muitos dos elementos que caracterizam o Capital Intelectual sejam evidenciados por meio das Demonstrações Contábeis divulgadas aos usuários externos da Contabilidade (ANTUNES e MARTINS, 2002).

Dadas as limitações que as normas contábeis impõem à Contabilidade Financeira, entende-se que todo o panorama que envolve a complexidade dos ativos intangíveis e do Capital Intelectual faz com que se direcionem os esforços da sua materialização para a Contabilidade Gerencial. Essa, por ser interna e não restrita às imposições legais, pode desenvolver modelos gerenciais para a identificação, registro e gestão dos elementos intangíveis que associados à estratégia das organizações podem conduzí-las a maior competitividade, como sugerem Johnson e Kaplan, (1996) e Kaplan e Norton, (1997).

Diante do exposto, é de se sugerir que os gestores na atualidade, por meio de seus modelos de gestão, contemplem esses elementos intangíveis fazendo uso do conhecimento como recurso e também como produto ou serviço gerado, a fim de otimizar as suas aplicações e de beneficiarem-se das suas conseqüências, obtendo condições para que atuem de forma competitiva num mundo de constantes e cada vez mais rápidas alterações. Mas, ao mesmo tempo, é de se perguntar se a Contabilidade das empresas está preparada para fornecer o suporte adequado em termos de disponibilizar as informações necessárias.

\section{OBJETIVO GERAL}

O objetivo principal desta pesquisa é verificar o tratamento, em termos de investimento, mensuração e gestão, dos elementos intangíveis em grandes empresas brasileiras, a fim de se investigar a adequação do Sistema de Informações Contábeis Gerenciais dessas empresas para a gestão do Capital Intelectual.

Para tanto, partiu-se da premissa de que o motivo subjacente para a realização de quaisquer investimentos em elementos intangíveis e para sua gestão reside na percepção dos gestores sobre a sua importância para as organizações e essa importância deve estar contemplada no modelo de gestão da empresa, por meio da sua missão, e as informações necessárias disponibilizadas no Sistema de Informações Contábeis Gerenciais da entidade. 


\subsection{Objetivos Específicos}

Especificamente, pretendeu-se:

- Identificar os elementos do Capital Intelectual nos quais as empresas da amostra investem.

- Verificar se os Sistemas de Informações Contábeis Gerenciais dessas empresas disponibilizam as informações sobre os investimentos nos elementos do Capital Intelectual.

- Identificar as razões para a não disponibilização de tais informações.

\section{REFERENCIAL TEÓRICO}

\subsection{O Capital Intelectual}

O Capital Intelectual está diretamente relacionado aos elementos intangíveis resultantes das atividades e práticas administrativas desenvolvidas pelas organizações para se adaptarem e atuarem na realidade atual (CRAWFORD, 1994; BROOKING, 1996; STEWART, 1998 e 2001; PABLOS, 2002; LEV, 2001, 2003; 2004).

$\mathrm{Na}$ visão dos referidos autores, esses investimentos trazem benefícios intangíveis às organizações e capacitam o seu funcionamento, agregando-Ihes valor e foram propiciados, principalmente, pelas revoluções nas áreas da tecnologia da informação e das telecomunicações que, por sua vez, também propiciam as condições atuais da Sociedade do Conhecimento.

Segundo Lev (2001), o Capital Intelectual é gerado pelos investimentos em três elementos: inovação, desenho organizacional diferenciado e recursos humanos.

De acordo com Roos, Roos, Edvinsson e Dragonetti (1997), o conceito de Capital Intelectual é exposto de duas formas, identificadas por positiva e negativa. Da forma positiva, o Capital Intelectual consiste no somatório do conhecimento dos seus membros e da materialização desse conhecimento em marcas, produtos e processos. A forma negativa conceitua o Capital Intelectual como 'alguma coisa' que cria valor, mas é intangível e representa a diferença entre o valor total da companhia e o seu valor financeiro.

Porém, ainda segundo os autores (ROOS, ROOS, EDINSSON, DRAGONETTI, 1997, p. 29), a melhor opção para o entendimento do conceito de Capital Intelectual é "distinguir os diferentes componentes desse nebuloso e abrangente conceito, pois ajuda além da compreensão do mesmo, a tra- zê-lo para o nível estratégico e operacional da organização".

\subsection{Classificação dos Elementos do Capital Intelectual}

Observam-se, na literatura, intitulações diferenciadas para se denominar os elementos que compõem o Capital Intelectual, tais como: Elementos Intangíveis, Ativos Intangíveis, Recursos Intangíveis e, ainda, Capital Intangível, conforme se pode verificar em Bontis, 2001; Brooking, 1996; Caddy, 2002; Crawford, 1994; Edvinsson e Malone, 1998; Johnson e Kaplan, 1996; Sveiby, 1998; Lev, 2001; 2003 e 2004.

Nas classificações, encontram-se os elementos de Capital Intelectual associados ao conhecimento e à capacidade de aprendizagem organizacional, à gestão de recursos humanos e, ainda, à tecnologia da informação, à marca, à liderança tecnológica, à qualidade dos produtos, aos clientes, ao marketing share, dentre outros (MOURITSEN, BUKH, LARSEN e JOHANSEN, 2002). Uma explicação para esse fato pode estar na própria natureza abstrata desses elementos que são gerados por elementos igualmente intangíveis, tendo o conhecimento tanto como recurso (insumo), quanto como produto de per si e que devem ser vistos isoladamente e também no conjunto, pois produzem sinergia.

Nos trabalhos publicados por Brooking (1996), Edvinsson e Malone (1998) e Sveiby (1998) encontram-se as primeiras classificações para os elementos que compõem o Capital Intelectual. O Quadro 1, a seguir, evidencia a classificação proposta por Brooking (1996).

No Quadro 2, tem-se a classificação segundo Edvinsson e Malone. Observa-se que, enquanto Brooking emprega a palavra ativo, os outros dois autores utilizam recurso para identificarem o mesmo objeto.

Comparativamente, pode-se observar que o Capital Estrutural definido por Edvinsson e Malone contém os Ativos de Mercado, de Propriedade Intelectual e de Infra-estrutura apontados por Brooking.

No Quadro 3, apresenta-se a classificação elaborada por Sveiby (1998) para esses mesmos elementos, tendo esse autor empregado a denominação de ativos intangíveis.

Dessa fase inicial até os trabalhos mais recentes, pode-se verificar que os autores concordam quanto à origem da formação do Capital Intelectual, adotam as classificações mencionadas, ou fazem pequenas alterações que não afetem sua essência. O que difere, de fato, são os propósitos dos estudos. Isso pode ser observado em Antunes, (1999); 


\section{CAPITAL INTELECTUAL}

\begin{tabular}{|c|c|l|}
\hline \multicolumn{2}{|c|}{ CAPITAL INTELECTUAL } \\
\hline \multirow{3}{*}{ Ativos de Mercado } & $\begin{array}{l}\text { Potencial que a empresa possui em decorrência dos intangíveis que estão relacionados } \\
\text { ao mercado, tais como: marca, clientes, lealdade dos clientes, negócios recorrentes, } \\
\text { negócios em andamento, canais de distribuição. }\end{array}$ \\
\cline { 2 - 3 } & Ativo Humano & $\begin{array}{l}\text { Benefícios que o indivíduo pode proporcionar para as organizações por meio da sua } \\
\text { expertise, criatividade, conhecimento, habilidade para resolver problemas, tudo visto de } \\
\text { forma coletiva e dinâmica. }\end{array}$ \\
\cline { 2 - 3 } & $\begin{array}{c}\text { Ativos de propriedade } \\
\text { intelectual }\end{array}$ & $\begin{array}{l}\text { Ativos que necessitam de proteção legal para proporcionarem às organizações benefí- } \\
\text { cios tais como: know-how, segredos industriais, copyright, patentes, design. }\end{array}$ \\
\cline { 2 - 3 } & Ativos de infra-estrutura & $\begin{array}{l}\text { Tecnologias, metodologias e processos empregados como: cultura organizacional, siste- } \\
\text { ma de informação, métodos gerenciais, aceitação ao risco, banco de dados de clientes. }\end{array}$ \\
\hline
\end{tabular}

Fonte: Adaptado de Brooking (1996, p.13-16).

Quadro 1- Classificação dos elementos que compõem o Capital Intelectual

\begin{tabular}{|c|c|c|}
\hline \multirow{3}{*}{ 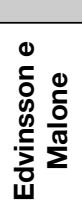 } & \multicolumn{2}{|r|}{ CAPITAL INTELECTUAL } \\
\hline & Capital Humano & $\begin{array}{l}\text { Combinação de conhecimento, habilidades, capacidade de inovação e capacidade dos } \\
\text { empregados em desenvolver tarefas. Valores, cultura e filosofia empresarial. }\end{array}$ \\
\hline & Capital Estrutural & $\begin{array}{l}\text { Hardware, software, banco de dados, estrutura organizacional, patentes, marca e tudo o } \\
\text { mais que dá suporte para a produtividade dos empregados. Clientes e relações desen- } \\
\text { volvidas com eles. }\end{array}$ \\
\hline
\end{tabular}

Fonte: Adaptado de Edvinsson e Malone (1997, p.11)

Quadro 2 - Classificação dos elementos que compõem o Capital Intelectual

\begin{tabular}{|c|c|c|}
\hline & \multicolumn{2}{|r|}{ ATIVOS INTANGÍVEIS } \\
\hline \multirow{3}{*}{ 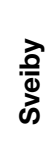 } & Estrutura Externa & Marcas, marcas registradas, relações com clientes e fornecedores, imagem da empresa. \\
\hline & Estrutura Interna & $\begin{array}{l}\text { Estrutura organizacional, estrutura gerencial, estrutura legal, sistemas, pesquisa e desen- } \\
\text { volvimento, software. }\end{array}$ \\
\hline & Competência Individual & Envolve a capacidade de agir em diversas situações para criar ativos tangíveis e intangíveis. \\
\hline
\end{tabular}

Fonte: Adaptado de Sveiby (1998, p. 14).

Quadro 3 - Classificação dos elementos que compõem os Ativos Intangíveis

Erickson e Rothberg, (2000); Roos, Bainbridge e Jacobsen, (2001); Bontis, (2001); Anson e Lussan, (2001); Caddy, (2002); Barbosa e Gomes, (2002).

Para fins deste estudo, adotou-se a classificação de Brooking (1996) por entender-se ser a mais adequada dada a identificação de quatro grupos que, em linhas gerais, contemplam, operacionalmente, os elementos mais evidenciados nas definições expostas pelos autores anteriormente citados.

\subsection{Sistemas de Informações Contábeis Gerenciais e a Controladoria}

Uma organização é uma coletividade formada por pessoas que têm a função de produzir bens e prestar serviços à sociedade, bem como atender às necessidades de seus participantes. Para tanto, as organizações possuem uma estrutura formada por indivíduos que se relacionam colaborando e dividindo o trabalho (BERNARDES E MARCONDES, 2003).

Em linhas gerais, os mesmos autores consideram que, para garantir a sua continuidade, uma organização deverá ser eficaz no sentido de produzir bens e prestar serviços, ser eficiente no sentido de aproveitar os recursos escassos e ser perene no tempo. Para tanto, deve ser capaz de desenvolverse no sentido de melhorar seu desempenho, crescer aumentando e aperfeiçoando seus produtos e serviços e, ainda, no caso de organizações econômicas, 
obterem retorno sobre o capital que compense os investimentos realizados.

Conseqüentemente, é de se supor que para que essas condições sejam atendidas as pessoas envolvidas na organização tenham, adequadamente, disponíveis as informações que irão balizar julgamentos, decisões, avaliações e previsões. Essas informações envolvem variáveis das mais diversas modalidades que fazem parte da realidade interna e externa da organização.

Por outro lado, alguns autores afirmam que o Sistema de Contabilidade Gerencial (SCG), na maioria das empresas, comprovou-se inadequado às condições de mudanças e de desafios competitivos, tecnológicos e mercadológicos atuais (ATKINSON et al., 2000).

Os autores supracitados justificam que, tradicionalmente, os Sistemas de Informações Contábeis (SIC) são limitados e sua maior função está na guarda e no registro das informações, apresentando pouca força na tomada de decisão e planejamento estratégico, mas devendo constituir-se na estrutura fundamental para o Sistema de Informação Gerencial (SIG) que, por sua vez, constitui-se em um agrupamento de sistemas que deveriam fornecer informações para apoio gerencial.

O aspecto da geração, e conseqüente disponibilização das informações para decisões estratégicas por parte dos SIG, pode ser observado como, ainda, deficiente na visão dos autores citados e também em Wu (1983); Kaplan e Norton (1997) e Lev (2001), segundo consta em Antunes (2004).

Por outro lado, Seldin et al. (apud SILVA, 2005) consideram que os avanços tecnológicos devem ser incorporados pelas organizações de forma imediata, não só para garantir a sua competitividade, mas, principalmente, para garantir sua sobrevivência no mercado. Nesse sentido, Santos (2003) considera que os softwares desenvolvidos para integrar os diversos setores empresariais podem contribuir para prontificar a informação necessária à gestão organizacional e, conseqüentemente, contribuir para que os SIG das empresas sejam eficientes.

Nesse contexto, a Controladoria é identificada como a área da organização responsável pela agregação e disponibilização das informações necessárias ao processo decisório (GUERREIRO 1989; NAKAGAWA, 1993; FIGUEIREDO e CAGGIANO, 1993; CATELLI, 1999; PELEIAS, 2002).

De acordo com Almeida, Parisi e Pereira (1999) e Martin (2002), a Controladoria apresentase como uma evolução natural e alternativa à Contabilidade Gerencial tradicional cuja base conceitual para modelar as informações destinadas aos gestores é inadequada, visto estar voltada para a realização de eventos passados, segundo a visão desses autores.

Portanto, Almeida, Parisi e Pereira (1999), Johnson e Kaplan (1996) e Martin (2002), advogam a necessidade de que as organizações, para atuarem num ambiente tal qual como caracterizado nos últimos anos e atingirem os resultados desejados, hão de simular eventos futuros que contemplem informações que dêem, também, condições preditivas, tendo em vista que um modelo basicamente financeiro não consegue propiciar as informações necessárias para dar apoio à gestão das empresas em suas maiores decisões.

Catelli (1999) ressalta que para o correto entendimento da Controladoria necessário se faz cindí-la em dois vértices: a Controladoria como ramo do conhecimento e a Controladoria como unidade administrativa. Em linhas gerais, a Controladoria como ramo do conhecimento é responsável pelo estabelecimento das bases teóricas e conceituais necessárias para a modelagem, construção e manutenção do Sistema de Informações Contábeis Gerenciais. A Controladoria como unidade administrativa é responsável pela coordenação e disseminação desse conhecimento e também atuar como órgão aglutinador e direcionador de esforços dos gestores a fim de acompanhar e conduzir a organização aos objetivos determinados (CATELLI, 1999; PELEIAS, 2002).

Martin (2002) considera que a moderna Controladoria se faz integrando o modelo explicativo básico da Contabilidade Gerencial com a identificação e a avaliação de variáveis que têm elevado impacto nos resultados das empresas, tais como: o valor dos produtos, os fatores ambientais setoriais e sistêmicos, os processos de trabalhos e os recursos tangíveis e intangíveis mobilizados.

Assim sendo, a Controladoria, fazendo uso dos princípios, conhecimentos e métodos oriundos de outras áreas do conhecimento, pode estabelecer as bases teóricas necessárias à sua atuação na organização e estruturar o sistema de informação gerencial de forma a contemplar as informações necessárias para conduzir as organizações ao cumprimento de sua missão.

\subsection{Modelos de Gestão e Modelos de Mensuração do Capital Intelectual}

Lev (2001, p. 17) considera que o Capital Intelectual "é um ativo intangível que, se gerenciado com sucesso, proporciona benefícios futuros para a empresa".

Sveiby (1998, p.196) identifica duas finalidades principais para que os intangíveis sejam avalia- 
dos tendo como referência as partes interessadas. $\mathrm{Na}$ apresentação externa, a empresa descreve-se da forma mais precisa possível para os envolvidos, clientes, credores, fornecedores, governo, acionistas e demais interessados pela informação contábil, a fim de que possam avaliar a qualidade de sua gerência. Na apresentação interna, a avaliação é feita para a gerência, que precisa conhecer o máximo possível a empresa para poder monitorar o seu progresso e tomar medidas corretivas quando necessário.

Entende-se que tanto o processo de mensuração quanto o de gestão do Capital Intelectual constituem-se em processos de avaliação, pois, independentemente dos objetivos pretendidos e dos critérios envolvidos para tanto, irá proceder-se a um julgamento sobre algum atributo.

Para fins deste estudo, adota-se que os modelos de gestão do Capital Intelectual são aqueles que visam atribuir valor no sentido qualitativo e quantitativo, segundo expõe Pereira (1999, p. 190), por meio de mensurações visando avaliar os resultados das atividades no processo de atingir alvos, segundo Guerreiro (1989, p.78). Dessa forma, os modelos de gestão do Capital Intelectual devem contemplar não apenas a identificação, mensuração e registro desses investimentos mas, também, o seu acompanhamento de forma a avaliar a expectativa de retorno desses ativos.

A título de exemplo de modelos desenvolvidos com essa finalidade tem-se o Navegador da Skandia (EDVINSSON e MALONE, 1998), o Cl-Index (ROOS, ROOS, EDVINSSON E DRAGONETTI, 1997), o Tecknology Broker's Cl Audit (BROOKING, 1996), o Intangible Asset Monitor (SVEIBY, 1998) e o Balanced ScoreCard (NORTON E KAPLAN, 1997).

A implementação e operacionalização desses modelos podem se dar por meio dos Sistemas Integrados de Gestão ou Enterprise Resource Planning (ERP), que se define como um sistema gerencial e contábil que permite uma visão integrada das áreas da empresa (SILVA, 2005), ou por softwares aplicativos desenvolvidos pelas empresas especificamente para essa finalidade.

Os modelos de mensuração do Capital Intelectual são entendidos como aqueles que visam atribuir um valor numérico e objetivo, preferencialmente, em valores monetários.

Como exemplos desses modelos têm-se como os mais citados na literatura: a Fórmula do Capital Intelectual da Skandia (EDVINSSON e MALONE, 1998), a Diferença entre o Valor de Mercado e o Valor Contábil (STEWART, 1998; SVEIBY, 1998; ROOS, ROOS, EDVINSSON e DRAGONETTI, 1997; EDVINSSON e MALONE, 1998; CADDY, 2002; HOPE e HOPE, 2000) e o Intangibles-Driven-Earnings (LEV, 1994).

\section{PROCEDIMENTOS METODOLÓGICOS}

\subsection{Tipo e Método de Pesquisa}

O presente estudo caracteriza-se como uma pesquisa exploratória, pois se buscou a obtenção de maiores conhecimentos sobre o tratamento que a Contabilidade de grandes empresas brasileiras dá aos investimentos em elementos do Capital Intelectual.

O método de pesquisa empregado foi o método qualitativo (GODOY, 1995). A metodologia utilizada para a análise das respostas obtidas foi a de análise de conteúdo que, segundo Bardin (1977) e Godoy (1995), é a mais apropriada para ser aplicada em estudos de natureza qualitativa.

A análise de conteúdo, de acordo com Bardin (1977), consiste em um conjunto de técnicas de análise das comunicações que utiliza procedimentos sistemáticos e objetivos de descrição e categorização das mensagens. Para tanto, complementa Godoy (1995), utilizam-se de técnicas quantitativas e/ou qualitativas, condensando os resultados em busca de padrões, tendências ou relações implícitas cuja interpretação deverá ir além do conteúdo manifesto dos documentos, pois o que interessa ao pesquisador é o conteúdo latente, ou seja, o sentido que está por trás do imediatamente aprendido.

Como forma de categorização adotou-se a matriz de análise de conteúdo, segundo Cerretto (2003), cuja metodologia segue, também, a firmada por Bardin (1977).

Para a determinação de freqüências e demais inferências estatísticas realizadas como apoio à análise de conteúdo das entrevistas, fez-se uso do software estatístico SPSS - Statistical Package for Social Sciences, versão 10.

\subsection{População e Amostra}

A população-alvo do estudo foi constituída pelas 150 maiores empresas, segundo a Revista Exame Melhores \& Maiores (2003), em função do volume de vendas referente ao exercício de 2002, segregadas por ramo de atividade (indústria, comércio e serviço) em nível nacional. A estratificação da população-alvo por ramos de atividade foi motivada pela conjectura de que poderia influir no volume de investimento em Capital Intelectual.

A amostra final foi composta por 30 empresas selecionadas da população-alvo em função da predisposição dos gestores em participar da pesquisa, além da facilidade de acesso e da ocasião caracteriza-se como uma amostra de conveniência e de tamanho suficiente para o método de pesquisa adotado. 
Objetivou-se, inicialmente, entrevistar os diretores financeiros, ou função similar, considerando que não existe um organograma padrão, ou ainda os presidentes das empresas no impedimento dos outros, por estar a Controladoria geralmente sob a responsabilidade da diretoria financeira.

Essa escolha deveu-se ao fato de se pretender verificar qual é o entendimento do conceito de Capital Intelectual por parte da alta direção da empresa e por executivos que supostamente decidem os investimentos a serem realizados, além de participarem do planejamento e das decisões estratégicas das empresas.

$\mathrm{O}$ instrumento de pesquisa utilizado foi um questionário contendo perguntas abertas e fechadas. As perguntas fechadas foram utilizadas para obter informações socio-demográficas e funcionais dos respondentes e sobre as características das empresas. As perguntas abertas foram utilizadas para buscar o entendimento dos gestores sobre o conceito de Capital Intelectual, identificar os elementos nos quais investem a título de Capital Intelectual, bem como identificar o enquadramento dado a esses elementos no processo de gestão das empresas.

\section{APRESENTAÇÃO E ANÁLISE DOS RESULTADOS}

\subsection{Caracterização das Empresas}

As empresas, foco deste estudo, classificamse dentre as 50 maiores empresas dos ramos de serviço, indústria e comércio segundo a classificação da Revista Exame Melhores \& Maiores (2003) e mostraram características bastante diversificadas. Na seqüência, apresenta-se a caracterização da amostra de empresas em relação a: localização geográfica, ramo de atividade, controle acionário, setor, tipo de empresa e quanto à negociação de ações em Bolsa de Valores.

A Figura 1 exibe a distribuição das empresas em função da sua localização geográfica, por Estados.

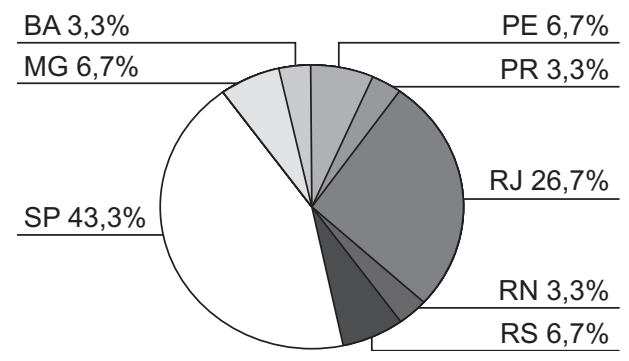

Figura 1 - Distribuição das empresas por Estado
Pode-se observar que a maior concentração de empresas está na região Sudeste, especificamente nos Estados de São Paulo e Rio de Janeiro totalizando $70 \%$. Esse fato retrata a realidade brasileira na qual os maiores centros produtivos estão concentrados na região Sudeste.

A Figura 2 evidencia que o Estado que concentrou os três ramos de atividade foi o Estado de São Paulo, seguido pelo Estado do Rio de Janeiro, que congregou empresas pertencentes à indústria e serviços.

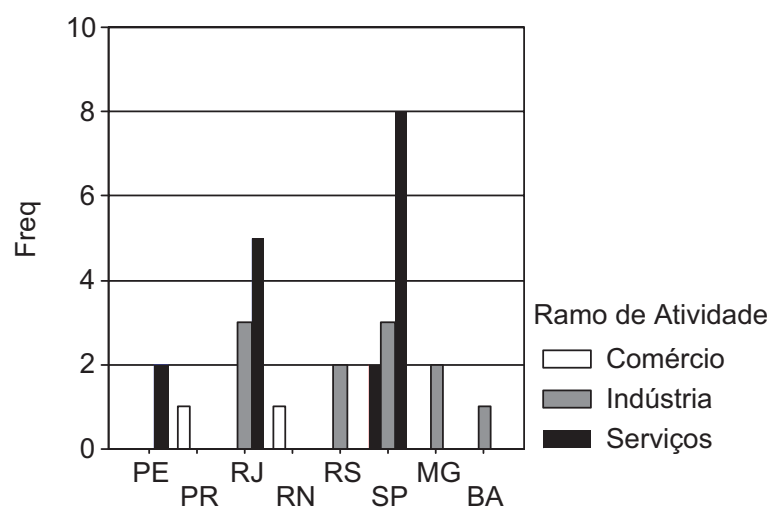

Figura 2 - Distribuição das empresas por Estado e ramo de atividade

Com relação ao controle acionário, verificouse a predominância do capital brasileiro $(73,3 \%)$, seguido pelo capital americano (10,0\%) (FIGURA 3). Os controles de capital italiano, francês, espanhol, alemão e americano/brasileiro apresentaram o mesmo percentual de 3,3\%, conforme se pode verificar por meio da Figura 3 na seqüência.

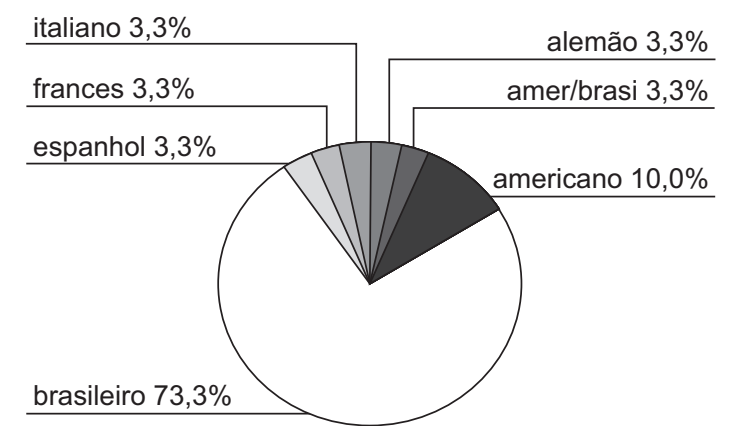

Figura 3 - Distribuição das empresas
segundo o controle acionário

A distribuição das empresas em função do seu setor de atuação (Figura 4), de acordo com a clas- 
sificação adotada pela Revista Exame Melhores \& Maiores (2003), evidencia que se obteve acesso a empresas de 15 setores diferentes. Os dados da figura, também, demonstram que os setores de serviços públicos e de transporte foram os que apresentaram maior concentração de empresas $(30,0 \%)$ seguido do setor químico/petroquímico (13,3\%).

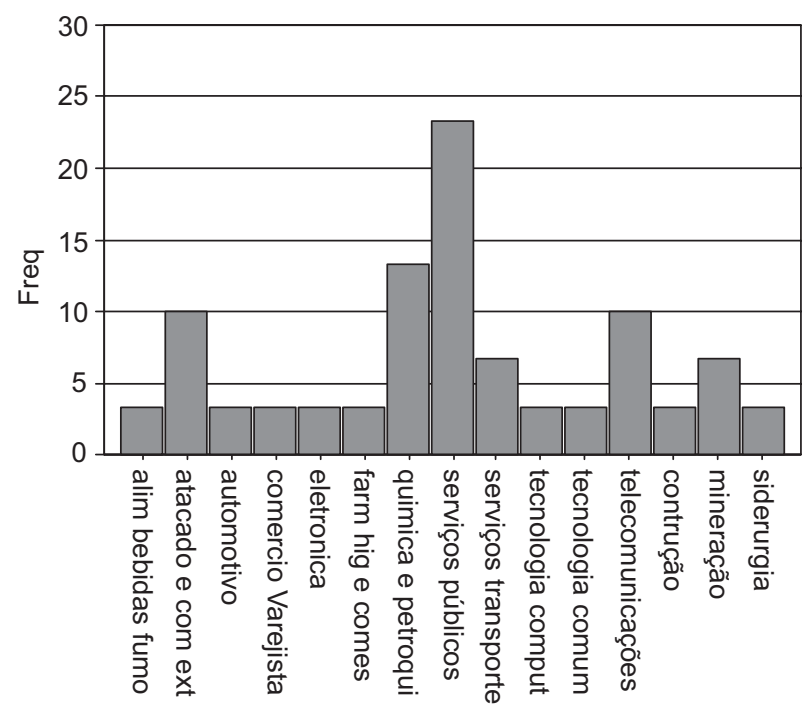

Figura 4 - Distribuição das empresas por setor

A Figura 5 exibe as empresas que possuem ações negociadas na Bolsa de Valores e as que não possuem em relação aos seus ramos de atividade.

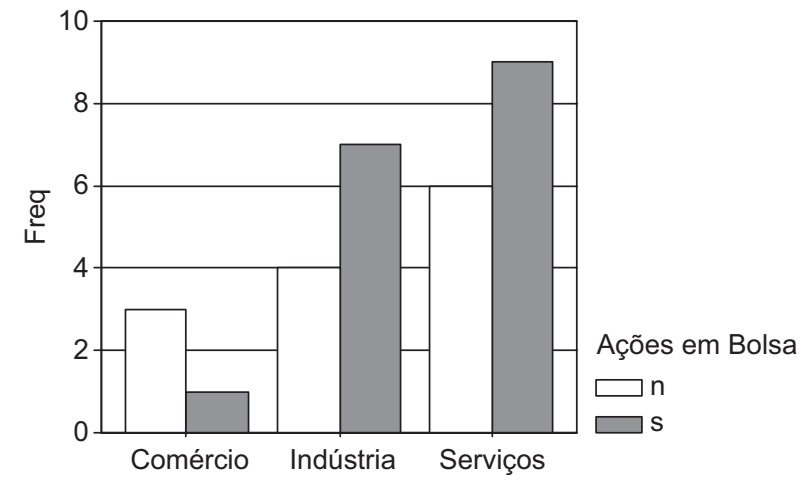

Figura 5 - Distribuição das empresas segundo ramo e ações negociadas

Pode-se observar que a maior concentração das empresas que possuem ações negociadas em Bolsa de Valores ficou no ramo de serviços, conforme exposto na Figura 5. Em termos absolutos, pode-se verificar que 17 das 30 empresas possuem ações negociadas na Bolsa de Valores.

Em relação às empresas serem de constituição pública ou privada, a Figura 6 evidencia que a grande maioria da amostra $(86,7 \%)$ é constituída por empresas privadas.

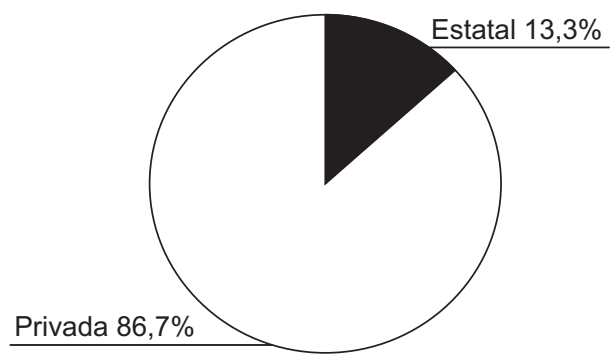

Figura 6 - Distribuição das empresas segundo o tipo

Em suma, a análise descritiva simples das características das empresas que compuseram a amostra demonstrou que a maioria das empresas estudadas está concentrada na região Sudeste, possui controle acionário brasileiro, é de constituição privada e pertence ao ramo de atividade de serviços e ao setor de serviços públicos. Com relação às ações negociadas na Bolsa de Valores, na distribuição obtiveram-se $56,7 \%$ das empresas de capital aberto.

\subsection{Caracterização dos respondentes}

A Tabela 1 exibe o perfil dos respondentes quanto ao sexo e à função exercida. A grande maioria dos respondentes $(95,8 \%)$ é do sexo masculino.

Considerando-se o objetivo inicial de serem entrevistados os diretores financeiros, ou função similar, pode-se verificar a predominância de diretores financeiros (17), presidentes (4) e controllers (5), do total de 30 respondentes. Atribui-se o acesso aos profissionais das duas outras funções (5 de recursos humanos e 1 da área de tecnologia da informação) ao encaminhamento dado à solicitação de entrevista pela própria empresa, embora se tenha solicitado a entrevista ao diretor financeiro. Esse fato sugere que para essas empresas o tema Capital Intelectual foi entendido como sendo da alçada das áreas de recursos humanos e de tecnologia.

Objetivo Específico 1: Identificação dos elementos do Capital Intelectual que recebem investimentos

Dos 30 gestores entrevistados somente 1 afir- 
Tabela 1- Perfil dos respondentes quanto a sexo e função

\begin{tabular}{|c|c|c|c|c|c|c|}
\hline \multirow{3}{*}{ Função } & \multicolumn{4}{|c|}{ Sexo do gestor } & & \\
\hline & \multicolumn{2}{|c|}{$\mathbf{F}$} & \multicolumn{2}{|c|}{ M } & \multicolumn{2}{|c|}{ Total } \\
\hline & Freg. & $\%$ & Freg. & $\%$ & Freg. & $\%$ \\
\hline Controladoria & 0 & .00 & 3 & $10.3 \%$ & 3 & $10.0 \%$ \\
\hline Diretoria financeira & 0 & .00 & 17 & $58.6 \%$ & 17 & $56.7 \%$ \\
\hline Presidência & 0 & .00 & 4 & $13.8 \%$ & 4 & $13.3 \%$ \\
\hline Recursos humanos & 1 & $100.0 \%$ & 4 & $13.8 \%$ & 5 & $16.7 \%$ \\
\hline Tecnologia informação & 0 & .00 & 1 & $3.4 \%$ & 1 & $3.3 \%$ \\
\hline Total & 1 & $100.0 \%$ & 29 & $100.0 \%$ & 30 & $100.0 \%$ \\
\hline
\end{tabular}

mou não realizar investimentos em Capital Intelectual justificando apenas que esse tema não se aplica a sua empresa. Ressalte-se que este respondente é da área de recursos humanos e a empresa pertence ao ramo de serviços.
Com relação às respostas dos outros 29 gestores, elaborou-se uma distribuição de freqüência dos elementos mais citados, agrupados em categorias por similaridade.

A Tabela 2 exibe esses resultados.

Tabela 2 - Freqüência dos elementos do Capital Intelectual

\begin{tabular}{l|c|c}
\multicolumn{1}{c|}{ Elementos } & Freq. & (\%) \\
\hline Treinamento e Desenvolvimento de Pessoal & 28 & 96,55 \\
\hline Produtos & 4 & 13,79 \\
\hline Infra-estrutura & 9 & 31,03 \\
\hline Imagem da empresa & 1 & 3,45 \\
\hline Patentes & 1 & 3,45 \\
\hline Responsabilidade Social & 1 & 3,45 \\
\hline Condições de trabalho & 1 & 3,45 \\
\hline
\end{tabular}

Em linhas gerais, pode-se verificar que 28 dos 29 respondentes citaram o elemento humano nas variações de investimentos em treinamento, desenvolvimento, instrução, formação e seleção de pessoal. A análise de conteúdo identificou, também, que desses 28 gestores, 20 citaram, inicialmente, apenas esse elemento, podendo-se sugerir que $\mathrm{Ca}$ pital Intelectual nessas empresas está diretamente relacionado ao elemento humano. Além disso, pode-se verificar que os demais gestores incluíram outros elementos relacionados à tecnologia, produto, processos, pesquisa \& desenvolvimento e suas variações, tal qual como apresentado na literatura.

Com relação ao volume investido nesses elementos, a Tabela 3 exibe a média anual desses investimentos, por empresa ${ }^{1}$. Com essa questão, pre- tendeu-se, também, obter subsídios para avaliar o nível de controle desses investimentos.

A análise das informações, disponibilizadas na Tabela 3, permite verificar que 15 dos 29 gestores informaram o valor investido tendo os demais justificado suas respostas assumindo tratar-se de informação estratégica ou que não dispunham dessa informação.

$\mathrm{O}$ fato de esses valores serem tratados como informação estratégica não é de se admirar. Muito da discussão sobre a obrigatoriedade da divulgação dessas informações, por meio do relatório anual, como demonstração complementar às Demonstrações Contábeis exigidas por lei, tem o ponto contra justamente na questão de beneficiar os concorrentes.

Entretanto, a contrapartida argumentada é que essa informação poderia representar uma informa- 
ção relevante aos acionistas, potenciais investidores, clientes e para a sociedade no geral. Em suma, não é uma questão resolvida no aspecto dos benefícios que traria às empresas.

Quanto ao não conhecimento do valor investido, identificado por meio da resposta: "não disponho desta informação", ou para aqueles que simplesmente não informaram o valor, não se pode precisar, ainda, se o gestor não soube informar porque desconhece a informação ou porque não há um sistema de controle para esses investimentos.
Comparando-se essas respostas aos elementos anteriormente identificados (Tabela 2), a análise de conteúdo permitiu verificar que dos 15 gestores, que souberam atribuir um valor aos investimentos, 13 tinham atribuído os investimentos às pessoas. Portanto, essa constatação pode sugerir que, em nível de gerência de Recursos Humanos, para essas empresas, existe um controle dos valores investidos em pessoal e o valor investido é de conhecimento de gestores que não pertencem à área de recursos humanos.

Tabela 3 - Empresas e valor médio anual dos investimentos

\begin{tabular}{|c|c|c|c|}
\hline Empresa & Valor Médio Anual Investido & Empresa & Valor Médio Anual Investido \\
\hline E 23 & $\mathrm{R} \$ 1.000 .000,00$ & E 13 & $\mathrm{R} \$ 10.000 .000,00$ \\
\hline E 10 & US\$ $11,000,000.00$ & E 21 & $\mathrm{R} \$ 200.000,00$ \\
\hline E 16 & Não disponho desta informação & E 17 & Não disponho desta informação \\
\hline E 22 & Informação estratégica não disponível & E 08 & $R \$ 3.500 .000,00$ \\
\hline E 01 & Informação estratégica não disponível & E 07 & $\mathrm{R} \$ 12.000 .000,00$ \\
\hline E 03 & $\mathrm{R} \$ 140.000,00$ & E 06 & $\mathrm{R} \$ 5.000 .000,00$ \\
\hline E 09 & Não disponho desta informação & E 20 & $\mathrm{R} \$ 95.000,00$ \\
\hline E 05 & $\mathrm{R} \$ 3.000 .000,00$ & E 14 & $\mathrm{R} \$ 1.500 .000,00$ \\
\hline E 04 & $\mathrm{R} \$ 650.000,00$ & E 24 & 0,00 \\
\hline E 11 & Não disponho desta informação & E 25 & $\mathrm{R} \$ 5.000 .000,00$ \\
\hline E 15 & Informação estratégica não disponível & E 26 & Não informou \\
\hline E 02 & Não disponho desta informação & E 27 & Não informou \\
\hline E 19 & "Difícil de ser quantificado" & E 28 & Não informou \\
\hline E 18 & $\mathrm{R} \$ 2.000 .000,00$ & E 29 & Não informou \\
\hline E 12 & $\mathrm{R} \$ 3.000 .000,00$ & E 30 & Não informou \\
\hline
\end{tabular}

Objetivo Específico 2: Investimentos em Capital Intelectual e Sistemas de Gestão

A fim de se verificar se os investimentos em Capital Intelectual estão contemplados no processo de gestão das empresas, por meio da existência de sistemas integrados de gestão elaborados pela Controladoria, estabeleceram-se algumas condições de acordo com o referencial teórico.

Para tanto, as empresas teriam que:

1. Ter definido indicadores para mensurar os elementos do Capital Intelectual.

2. Possuir sistema de gestão integrado e específico para eles.

3. Ter os elementos investidos em consonância com a Missão fixada para a empresa.

4. Ter a Controladoria (ou área financeira) como gestora desse processo.

\section{- Condição 1:}

Com relação à primeira condição (Existência de indicadores para mensurar os elementos do Capital Intelectual), dos 24 gestores que responderam a essa questão, $62,5 \%$ deles, o equivalente a 15 gestores, responderam positivamente e 9 gestores $(37,5 \%)$ afirmaram não terem atribuído indicadores para tal fim.

O Quadro 4 apresenta as respostas obtidas junto a esses 15 gestores, incluindo os tipos de indicadores atribuídos.

- Condição 2:

Com relação à segunda condição (Existência de sistemas de gestão integrados e específicos), o Quadro 5 exibe as respostas obtidas.

Para análise dessa condição, julgou-se oportuno fazer uma distinção entre o que se considera 


\begin{tabular}{|l|l|l|}
\hline Fonte & $\begin{array}{c}\text { Existência de } \\
\text { Indicadores }\end{array}$ & \multicolumn{1}{c|}{ Tipos de Indicadores } \\
\hline E 23 & Sim & Verificamos nos resultados, volume de vendas, EBITDA e mais alguns indicadores de performance. \\
\hline E 10 & Sim & Tudo avaliamos pelo ROI - Retorno s/ Investimento. Temos vários indicadores de performance. \\
\hline E 16 & Sim & Vários indicadores. \\
\hline E 22 & Sim & Indicadores de produtividade, de performance. \\
\hline E 01 & Sim & Os indicados pelo Balanced Scorecard. \\
\hline E 05 & Sim & Número de horas trabalhadas por empregado. Temos vários indicadores, trabalhamos com indicadores. \\
\hline E 04 & $\operatorname{Sim}$ & Os indicados pelo Balanced Scorecard. \\
\hline E 11 & $\operatorname{Sim}$ & Indicadores de produtividade. \\
\hline E 15 & $\operatorname{Sim}$ & Indicadores diários de desempenho. \\
\hline E 02 & $\operatorname{Sim}$ & Calculamos para cada projeto que leva componentes do Capital Intelectual o EBITDA. \\
\hline E 19 & $\operatorname{Sim}$ & Os indicados pelo Balanced Scorecard. \\
\hline E 18 & $\operatorname{Sim}$ & $\begin{array}{l}\text { Média de vendas por executivos. } \\
\text { Geração de riqueza. }\end{array}$ \\
\hline E 12 & $\operatorname{Sim}$ & $\begin{array}{l}\text { São vários dependendo do relacionado à produtividade individual dos profissionais. Ex.: tempo de } \\
\text { resposta / número de falhas no processo. }\end{array}$ \\
\hline E 13 & $\operatorname{Sim}$ & ROI - Retorno s/ investimento. \\
\hline E 14 & $\operatorname{Sim}$ & Indicadores que refletem o quantitativo da força de trabalho que participou de treinamentos. \\
\hline
\end{tabular}

\section{Quadro 4 - Existência de indicadores e tipos de indicadores}

como sistemas de gestão integrados e específicos para a gestão dos elementos intangíveis e sistemas integrados de gestão comumente encontrado nas empresas, pois, conforme consideram Johnson e Kaplan (1996), os elementos intangíveis, bem como os benefícios econômicos que deles advêm, não têm sido explorados ou percebidos pelos SIG gerados pela Contabilidade Gerencial, sendo entendido como uma falha que compromete o papel da lucratividade de curto prazo como indicador confiável. Para os autores, existe a necessidade de não se limitar apenas ao cálculo do valor econômico ou individual, devendo contemplar o valor dos ativos intangíveis.

Dessa forma, assume-se que os sistemas de gestão integrados e específicos para a gestão dos elementos intangíveis são aqueles estruturados para identificar, mensurar, registrar e avaliar a contribuição desses elementos para a geração de valor das empresas. Esses sistemas podem ser alguns daqueles já existentes, elaborados segundo a filosofia do $\mathrm{Ba}$ lanced Scorecard ou Navegador da Skandia, ou softwares aplicativos desenvolvidos pelas empresas.

\begin{tabular}{|l|l|l|}
\hline Fonte & $\begin{array}{c}\text { Existência } \\
\text { de modelos } \\
\text { específicos }\end{array}$ & Características do modelo \\
\hline E 23 & Sim & $\begin{array}{l}\text { Existem vários, mas não interligados. Cada área possui o seu planejamento e o acompanha pelo } \\
\text { seu sistema. }\end{array}$ \\
\hline E 10 & Sim & Todos foram desenvolvidos por nós. Estamos com uma consultoria para aprimorar esses modelos. \\
\hline E 16 & Sim & O Balanced Scorecard e mais outros sistemas por unidades de negócio. \\
\hline E 22 & Sim & Um sistema desenvolvido por nós, mas não posso dizer que esteja totalmente integrado. \\
\hline E 01 & Sim & O Balanced Scorecard. \\
\hline E 05 & Sim & $\begin{array}{l}\text { Temos os indicadores para cada setor da empresa e um sistema que liga tudo corporativo. Planeja- } \\
\text { mento global. }\end{array}$ \\
\hline E 04 & Sim & O Balanced Scorecard. \\
\hline E 15 & Sim & Sistemas interligados com interfaces com várias áreas. \\
\hline E 02 & Sim & Um sistema integrado desenvolvido pela empresa. \\
\hline
\end{tabular}




\begin{tabular}{|c|c|l|}
\hline Fonte & $\begin{array}{c}\text { Existência } \\
\text { de modelos } \\
\text { específicos }\end{array}$ & \multicolumn{1}{c|}{ Características do modelo } \\
\hline E 19 & Sim & $\begin{array}{l}\text { Usamos o Balanced Scorecard (BSC), não só para coleção de indicadores, mas como uma ferra- } \\
\text { menta de transformação e acompanhamento da estratégia. }\end{array}$ \\
\hline E 18 & Sim & Liga a estratégia através das competências organizacionais aos resultados a serem alcançados. \\
\hline E 12 & Sim & PEP - Processo de Excelência de Performance. \\
\hline E 13 & $\operatorname{Sim}$ & $\begin{array}{l}\text { Composto dos mecanismos de acompanhamento da gestão; avaliação de investimentos; gerencia- } \\
\text { mento de custos e receitas e outros. }\end{array}$ \\
\hline E 14 & Sim & Balanced Scorecard (BSC). \\
\hline
\end{tabular}

Quadro 5 - Existência de modelos e suas características

O Quadro 5 evidencia que $58,3 \%$ dos gestores, o correspondente a 14 gestores, afirmaram existir um sistema de gestão.

Entretanto, analisando-se a descrição feita pelos gestores sobre as características dos sistemas implantados, tendo por base a literatura e a definição anteriormente exposta, pode-se identificar que em 11 (45,83\%,) das 14 empresas (E 10; E 16; E 01; E 05; E 04; E 15; E 02; E 19; E 18; E 12 e E 14), existe um sistema que pode se assemelhar a um outro que também gerencie os elementos do Capital Intelectual, mais notadamente aquelas que utilizam o Balanced Scorecard. Essas empresas foram destacadas no Quadro 5.

\section{- Condição 3:}

A fim de se verificar o atendimento à terceira condição (Elementos investidos em consonância com a Missão da empresa), para as 11 empresas identificadas como aquelas que possuem o sistema de gestão semelhante ao estabelecido para fins deste estudo, procedeu-se a uma análise comparativa, identificando-se em suas missões os elementos contemplados como recebedores de investimentos a título de Capital Intelectual. O Quadro 6 evidencia o resultado dessa análise.

Pode-se observar que 5 das 11 empresas citadas satisfizeram à terceira condição, ou seja, podem-se identificar elementos que permitiram fazer o

\begin{tabular}{|c|c|c|}
\hline Empresa & Elementos identificados & Missão \\
\hline E 16 & $\begin{array}{l}\text { Marca, Imagem Res- } \\
\text { ponsabilidade Social, } \\
\text { Tecnologia, Patentes, } \\
\text { Treinamento e Qualifica- } \\
\text { ção dos Funcionários. }\end{array}$ & $\begin{array}{l}\text { Atuar de forma segura e rentável nas atividades da indústria de óleo, gás e energia, } \\
\text { nos mercados nacional e internacional, fornecendo produtos e serviços de qualida- } \\
\text { de, respeitando o meio ambiente, considerando os interesses dos seus acionistas e } \\
\text { contribuindo para o desenvolvimento do País. }\end{array}$ \\
\hline E 01 & $\begin{array}{l}\text { Treinamento dos } \\
\text { funcionários }\end{array}$ & $\begin{array}{l}\text { Criar valor para seus acionistas com a otimização contínua de seus custos e da } \\
\text { qualidade de seus produtos e serviços. Para atingir esses objetivos, conta com o } \\
\text { grande patrimônio de competências gerenciais e técnicas de seus recursos huma- } \\
\text { nos e trabalha pela sua valorização contínua, mediante uma organização sempre } \\
\text { mais ágil e dinâmica. }\end{array}$ \\
\hline E 02 & $\begin{array}{l}\text { Pessoas, Infra-estrutura, } \\
\text { Tecnologia, Produtos }\end{array}$ & $\begin{array}{l}\text { Revolucionar a maneira como pessoas e empresas se comunicam, oferecendo } \\
\text { soluções inovadoras em telecomunicações, superando assim as expectativas de } \\
\text { clientes, funcionários e acionistas. }\end{array}$ \\
\hline E 19 & $\begin{array}{l}\text { Marca, Relacionamento } \\
\text { com cliente, Treinamento, } \\
\text { Tecnologia da Informação } \\
\text { e Processos, Condições } \\
\text { de Trabalho, Knowledge } \\
\text { Management, Inovação. }\end{array}$ & $\begin{array}{l}\text { Os Princípios da nossa empresa proporcionam aos colaboradores conceitos para } \\
\text { pensar e agir de forma empreendedora. Eles estabelecem uma base para uma mu- } \\
\text { dança cultural que sustenta o programa top+, e indicam o esforço que é esperado } \\
\text { de cada um dos colaboradores na direção da melhoria contínua: Clientes, Inovação, } \\
\text { Valor, Responsabilidade. }\end{array}$ \\
\hline E 12 & $\begin{array}{l}\text { Treinamentos Funcionais, } \\
\text { Gerenciais e Externos. } \\
\text { Educação e Qualidade }\end{array}$ & $\begin{array}{l}\text { Criar condições para que as pessoas identifiquem as melhores maneiras de fazer } \\
\text { um trabalho de excelência. Ajudar as pessoas a encontrar modos melhores de } \\
\text { realizar um grande trabalho - avançando constantemente em tecnologias, produtos } \\
\text { e serviços relativos a documentos que melhoram os processos de trabalho e os } \\
\text { resultados comerciais dos clientes. }\end{array}$ \\
\hline
\end{tabular}


julgamento de que a filosofia do Capital Intelectual está contemplada em seu modelo de gestão.

- Condição 4:

Com relação à quarta e última condição (ter a Controladoria, ou área financeira como gestora des- se processo) a análise das respostas dos 11 gestores que anteriormente (Quadro 5) afirmaram existir em suas empresas sistemas de gestão para os investimentos em elementos do Capital Intelectual, permitiu verificar os seguintes resultados:

Tabela 4 - Área responsável pela gestão do modelo

\begin{tabular}{c|c|c}
\hline Área na Empresa & Freqüência & (\%) \\
\hline Todas as áreas & 1 & 9,1 \\
\hline Controladoria & 4 & 36,3 \\
\hline Diretoria Financeira & 2 & 18,2 \\
\hline Presidência & 1 & 9,1 \\
\hline Recursos Humanos & 2 & 18,2 \\
\hline Recursos Humanos e Diretoria Financeira & 1 & 9,1
\end{tabular}

O exame dos dados da Tabela 4 indica que a área mais citada para fazer a gestão dos sistemas identificados pelos gestores como idealizados para a gestão do Capital Intelectual foi a da Controladoria, seguida pela Diretoria Financeira e de Recursos Humanos.

Objetivo Específico 3: Justificativas para a não existência de sistemas de gestão do Capital Intelectual
O Quadro 7 evidencia as justificativas dadas pelos gestores para a não existência de sistemas formalizados para a gestão dos investimentos realizados em Capital Intelectual e, também, a área que considerariam mais indicada para a gestão do sistema, quando de sua implantação.

Pode-se verificar que nas 10 empresas em que não existe esse sistema:

\begin{tabular}{|c|c|c|}
\hline Fonte & Motivos para a não existência & Área mais indicada \\
\hline E 20 & Estamos nos estruturando para este fim. & Recursos Humanos. \\
\hline E 06 & $\begin{array}{l}\text { Ao meu ver, dificuldade em mensurar ganhos financeiros com ativos intan- } \\
\text { gíveis. Existem maneiras não formais de se medir esse tipo de investimento, } \\
\text { tais como grau de satisfação de funcionários, redução de custos por melho- } \\
\text { rias de processos. }\end{array}$ & Controladoria em conjunto com $\mathrm{RH}$. \\
\hline E 07 & Estamos em fase de estudo. & Não respondeu. \\
\hline E 08 & Está em desenvolvimento. & Gestão de pessoas. \\
\hline E 17 & $\begin{array}{l}\text { Ainda estamos em fase de implantação, mas já nos preocupamos com inves- } \\
\text { timentos na área. No entanto, não há, por enquanto, critérios de mensuração } \\
\text { aplicados. }\end{array}$ & Recursos Humanos. \\
\hline E 21 & $\begin{array}{l}\text { Estamos construindo uma base de indicadores. Há indicadores contempla- } \\
\text { dos no Sistema de Gestão de Qualidade entre os quais ainda não estão os } \\
\text { retornos sobre os investimentos nos elementos do Capital Intelectual. }\end{array}$ & Não respondeu. \\
\hline E 11 & Estamos em um processo complicado de mudanças. & Diretoria Financeira. \\
\hline E 09 & Não tinha pensado nisso, você me deu uma boa idéia. & Controladoria. \\
\hline E 03 & $\begin{array}{l}\text { Não, eu nunca fiz isso e acho que seria uma boa preocupação tentar medir } \\
\text { esses investimentos. Talvez Recursos Humanos tenha alguma coisa, mas } \\
\text { não é um modelo conjunto. }\end{array}$ & Diretoria Financeira. \\
\hline E 25 & Não justificou. & Não identificou. \\
\hline
\end{tabular}


- em cinco delas o sistema encontra-se em fase de elaboração;

- em uma delas foi alegada a dificuldade de se mensurar ganhos financeiros com os investimentos em ativos intangíveis;

- em outra foi alegada a fase de mudança pela qual estão passando;

- em uma o gestor demonstrou surpresa de que isso pudesse ser feito;

- em outra o gestor desconhecia a existência e

- um gestor não respondeu o motivo.

Com relação à área mais indicada para exercer a gestão, caso o sistema fosse ser implantado, 3 gestores não responderam, 3 gestores consideraram a área de Recursos Humanos, 2 gestores consideraram a área Financeira, 1 gestor considerou a Controladoria e 1 gestor considerou a Controladoria em conjunto com a área de Recursos Humanos.

Admitindo-se a Controladoria como pertencente à área Financeira, pode-se verificar que as áreas de Recursos Humanos e de Controladoria receberam a mesma quantidade de indicações, 50\% cada uma, e uma indicação foi dada para as duas áreas em conjunto.

\section{CONSIDERAÇÕES FINAIS}

Este estudo objetivou verificar o tratamento, em termos de investimento, mensuração e gestão, que os investimentos em elementos do Capital Intelectual recebem da Contabilidade por meio da Controladoria, em grandes empresas brasileiras, de modo a se investigar a adequação dos Sistemas de Informações Contábeis Gerenciais para a gestão do Capital Intelectual.

Assumiu-se a Controladoria como uma evolução natural da Contabilidade, tendo em vista as mudanças que ocorreram nos ambientes próximo, remoto e operacional das empresas e, portanto, entendida como a área da empresa mais adequada para identificar, avaliar e mensurar os elementos que hoje contribuem para o desempenho empresarial e, também, para disponibilizar as informações necessárias à gestão das empresas no cumprimento de sua missão.

Considerando-se as limitações inerentes ao método qualitativo de pesquisa, utilizado neste estudo, a análise das respostas obtidas junto aos gestores da amostra permitiu verificar que eles consideram importante os investimentos em elementos do Capital Intelectual e investem nos elementos tal como conceituados pela literatura, tendo apenas um gestor afirmado não realizar tais investimentos.

Com relação à segmentação das empresas alvo de estudo nos três ramos de atividade, pode-se verificar que os resultados das análises realizadas contrapõem-se à crença de que as empresas que estão mais sujeitas aos efeitos dos elementos intangíveis e, portanto, realizam mais investimentos, são aquelas que pertencem ao setor de serviços ou de alta tecnologia (HOPE e HOPE, 2000; QUINN, 1992 e SVEIBY, 1998), por consumirem maior quantidade do recurso do conhecimento.

Os resultados confirmam a visão compartilhada por Stewart (1998), Sveiby (1998) e Kaplan e Norton (1997), de que atualmente é muito difícil encontrar um único setor, empresa ou organização de qualquer espécie que não tenha passado a fazer uso intensivo dos elementos intangíveis e não se tenha tornado dependente do conhecimento como fonte de atração para consumidores e clientes e da tecnologia da informação como instrumento gerencial.

Adicionalmente, entende-se que as diferentes combinações de fatores, tais como ramo de atividade e tipo de produto, tempo de vida da empresa, competitividade do setor, posição ocupada pela empresa no mercado, estilo de gestão, dentre outros, devam explicar os resultados obtidos, podendo-se inferir que, enquanto para algumas empresas os investimentos em Capital Intelectual podem se caracterizar como fator de diferenciação, para outras podem significar apenas a sua sobrevivência/ permanência no mercado.

Verificou-se, também, que o elemento mais vezes citado foi o elemento humano, o que pode sugerir que para essas empresas o Capital Intelectual está diretamente relacionado a ele. Esse fato vem ao encontro do pensamento de Sveiby (1998) para quem o elemento humano é o gerador de todos os demais elementos intangíveis que resultam nas estruturas internas e externas.

Outro aspecto importante a ressaltar é o fato do desconhecimento do valor investido, anualmente, nos elementos identificados como recebedores de investimentos a título de Capital Intelectual. Alguns gestores alegaram tratar-se de informação estratégica e, outros, desconhecer o valor. Nesse último caso, não se pode afirmar que desconhecem porque o Sistema de Informação Contábil não contempla o seu controle efetivo ou porque não sabem mesmo.

Entretanto, exceção se fez quando esses investimentos foram identificados ao elemento humano. Nesse caso, verificou-se a existência de um certo controle por parte da área de Recursos Humanos, sugerido por meio da quantificação e informação dos valores médios anualmente investidos em pessoas e de conhecimento de gestores que não pertencem à área de recursos humanos, em sua maioria. 
Com relação à adequação do Sistema de Informações Contábeis Gerenciais para a gestão desses investimentos, pode-se verificar que $62,5 \%$ dos gestores afirmaram atribuir indicadores para avaliar os investimentos realizados e $58,3 \%$ deles afirmaram existir em suas empresas sistemas integrados para a gestão desses elementos (o correspondente a 14 empresas).

Entretanto, apesar de os indicadores identificados pelos gestores terem sido considerados adequados para alguns dos elementos que caracterizam o Capital Intelectual, tendo como base a literatura, não se pode afirmar o mesmo quanto aos sistemas existentes para a sua gestão.

Considerando-se as condições estabelecidas neste estudo, pode-se identificar que em 11 empresas os sistemas estão próximos aos modelos desenvolvidos e constantes da teoria, anteriormente citados. Para essas empresas, a Controladoria foi a área identificada como a responsável pela gestão do modelo. Ainda segundo as condições estabelecidas neste estudo, pode-se observar que em 5 dessas 11 empresas os elementos investidos estão associados à missão das empresas.

Entretanto, isso não significa afirmar que nessas empresas não existam sistemas integrados de gestão. Alguns gestores afirmaram desenvolver seus próprios sistemas, embora tenham assumido não serem completos em termos de elementos do Capital Intelectual, especialmente no controle dos investimentos realizados. Os indicadores empregados são alguns dos sugeridos nos modelos de gestão do Capital Intelectual. Outros gestores afirmaram que estão dedicando esforços no sentido de desenvolver modelos que contemplem, também, a gestão dos elementos intangíveis.

De fato, é de conhecimento geral a grande variedade de sistemas e softwares aplicativos que o mercado desenvolveu para esse fim. Muitos desses sistemas contemplam medidas de produtividade e medidas qualitativas, principalmente o Balanced Scorecard, que foi identificado em 5 das 30 empresas pesquisadas. A importância que o desenvolvimento do Balanced Scorecard representou para a gestão de empresas contemporâneas é indiscutível. O mesmo pode-se dizer do Navegador da Skandia, a despeito de sua pouca divulgação e aplicação, pelo menos no Brasil, pelo que se tem conhecimento. Entretanto, os próprios idealizadores dos modelos (KAPLAN e NORTON, 1997 e EDVINSSON e MALONE, 1997) ainda questionam a existência de um perfeito entendimento do Capital Intelectual por parte dos gestores que possibilite, ao menos, a aplicação desses softwares aplicativos nos sistemas de gestão integrada em suas empresas.
Deve-se ressaltar que tanto os modelos constantes da literatura, quanto os sistemas adotados pelos gestores da amostra, não contemplam a associação dos investimentos aos retornos financeiros e econômicos que deles se espera advir. Estão baseados na crença de que os investimentos em Capital Intelectual trazem retornos positivos a longo prazo, conforme advogam, veementemente, Sveiby (1998), Edvinsson e Malone (1998), Stewart, (1998), dentre outros.

Essas evidências contribuem para corroborar a visão de Atkinson et al. (2000) que ressaltam a inadequação do Sistema de Informação Contábil Gerencial para as condições de mudanças e de desafios competitivos, tecnológicos e mercadológicos existentes atualmente.

Adicionalmente, essa pesquisa demonstrou que os gestores apresentam uma predisposição positiva ao tema. Isso significa que, caso Ihes seja disponibilizado algum sistema que permita a gestão do Capital Intelectual, estariam dispostos a implementá-lo em suas empresas, pois o consideram importante por propiciar o controle dos investimentos, tendo sido a Controladoria a área mais indicada para gerenciar o sistema que venha a contemplar a gestão dos elementos intangíveis de forma integrada. Por outro lado, alguns gestores afirmaram não ter, ainda, pensado no tema, embora o tenham considerado igualmente importante, e outros demonstraram um certo ceticismo por considerarem o tema de extrema complexidade.

Em suma, a pesquisa permitiu verificar que a grande maioria dos gestores da amostra realiza investimentos em elementos do Capital Intelectual e, ao mesmo tempo, que na maioria das empresas não existe um sistema implementado para avaliar o retorno desses investimentos e nem a quantificação correta dos valores investidos.

Em vista disso, pode-se inferir que a não existência de um controle efetivo possa conduzir os gestores a não investir, corretamente, nesses elementos por não terem à disposição um instrumento que permita avaliar se o retorno obtido foi, ao menos, o retorno esperado. Dessa forma, os investimentos realizados podem conduzir a gastos desnecessários, à não otimização dos recursos empregados, à subutilização dos recursos disponíveis e gerados, à não capitalização dos recursos e, em última instância, a perdas inestimáveis.

Em suma, tem-se, neste estudo, uma indicação, por parte de gestores, que em sua maioria exerce função executiva na alta gestão financeira de grandes empresas brasileiras, de demanda por informações sobre os investimentos em elementos intangíveis. Aliado a isso, tem-se, igualmente, verificado na 
mídia a procura, pelos analistas financeiros, por informações sobre os investimentos realizados em ativos intangíveis pelas empresas que possuem ações negociadas em Bolsa de Valores (FARIA, 2004).

Considerando-se a intangibilidade de alguns dos elementos do Capital Intelectual e, principalmente, a intangibilidade do produto gerado por esses elementos e, ainda, o volume de investimento relativamente alto que demandam, é de se supor haver a real necessidade de acompanhamento que eles requerem. Entende-se que a Controladoria, como ramo do conhecimento (CATELLI, 1999) e como um sistema especial de controle e de avaliação de desempenho, deve contemplar os novos requisitos exigidos pela realidade empresarial atual.

Digno de nota que as conclusões obtidas neste estudo estejam circunscritas à amostra adotada, não permitindo, portanto, generalizações, mas dão origem a conjecturas consistentes a serem investigadas por meio de métodos quantitativos adequados.

\section{REFERÊNCIAS BIBLIOGRÁFICAS}

ALMEIDA, Lauro Brito; PARISI, Cláudio; PEREIRA, Carlos Alberto. Controladoria. In: CATELLI, Armando (Org.). Controladoria: uma abordagem da gestão econômica. São Paulo: Atlas, 1999.

ANSON, Weston; LUSSAN, Jay D.. Intellectual Capital in liquidation. Secured lender, v. 57, n. 6, p. 52-55, nov./dec. 2001

ANTUNES, Maria Thereza P. Contribuição ao entendimento e mensuração do Capital Intelectual. 1999. Dissertação (Mestrado em Contabilidade) - Faculdade de Economia, Administração e Contabilidade da Universidade de São Paulo, São Paulo.

A influência dos investimentos em Capital Intelectual no desempenho das empresas: um estudo baseado no entendimento de gestores de grandes empresas brasileiras. 2004.Tese (Doutorado em Contabilidade) - Faculdade de Economia, Administração e Contabilidade da Universidade de São Paulo, São Paulo.

MARTINS, Eliseu. O Capital Intelectual integra o Goodwill. IOB - Informações Objetivas: Temática Contábil e Balanços, n. 51, p. 1-6, 2002

ATKINSON, Anthony A.; BANKER, Rajiv D.; KAPLAN, Robert S.; YOUNG, S. Mark. Contabilidade gerencial. São Paulo: Atlas, 2000.

BARBOSA, José Geraldo; GOMES, Josir Simeone. Um estudo exploratório do controle gerencial de ativos e recursos intangíveis em empresas brasileiras. Revista de Administração Contemporânea, São Paulo, v. 6, n. 2, p.29-48, maio/ago. 2002.

BARDIN, Laurence. Análise de conteúdo. Lisboa: Edições 70, 1977.

BERNADES, Cyro; MARCONDES, Reynaldo C.. Teoria geral da administração. 3 ed. São Paulo: Saraiva, 2003.

BONTIS, Nick. Assessing knowledge assets: a review of the models used to measure intellectual capital. International Journal of Management Review, United Kingdom, v. 3, n. 1, p. 41-60, 2001.

BOULTON, Richard E.S.; LIBERT, Barry D.; SAMEK, Steve M. Cracking the value code: how successful businesses are creating wealth in the New Economy. New York: HarperCollins, 2000.

BROOKING, Annie. Intellectual Capital: core asset for the third millennium enterprise. Boston: Thomson Publishing Inc., 1996.
CADDY, lan. Issues concerning intellectual capital metrics and measurement of intellectual capital. Singapore Management Review, v.24, n. 3, p.77-88, 2002.

CATELLI, Armando. (Org.) Controladoria: uma abordagem da gestão econômica GECON. São Paulo: Atlas, 1999.

CERRETTO, C.. A construção da matriz de análise de conteúdo. In: NASSIF, Vania Maria Jorge. Manual de trabalho de graduação interdisciplinar. São Paulo: Mackenzie, 2003.

CRAWFORD, Richard. Na era do capital humano. São Paulo: Atlas, 1994

DRUCKER, F. Peter. Sociedade Pós-Capitalista. São Paulo: Pioneira, 1993.

EDVINSSON, L.; MALONE, M. S.. Capital Intelectual. New York: Makron Books, 1998.

ERICKSON, Scott G.; ROTHBERG, Helen N.. Intellectual Capital and competitiveness: guidelines for policy. Competitiveness Review, v. 10, n. 2, p. 192-8, New York, 2000.

FARIA, Valter. Ativos intangíveis, de onde vem esse valor invisível. Revista Mercado de Capitais. São Paulo: APIMEC, ano XII, n.96, jul-ago-set, 2004.

FIGUEIREDO, S.; CAGGIANO, P.. Controladoria: teoria e prática. São Paulo: Atlas, 1993.

GODOY, Arilda Schmidt. Introdução à pesquisa qualitativa e suas possibilidades. Revista de Administração de Empresas da EAESP/FGV, São Paulo, v.35, n.2, p. 57-63, mar./abr. 1995.

GUERREIRO, R.. Modelo conceitual de sistema de informação de gestão econômica. 1989. Tese (Doutorado em Controladoria e Contabilidade). Faculdade de Economia, Administração e Contabilidade da Universidade São Paulo, São Paulo.

HOPE, Jeremy; HOPE, Tony. Competindo na terceira onda. Rio de Janeiro: Campus, 2000.

IUDÍCIBUS, Sergio de. Teoria da Contabilidade. 4 ed. São Paulo: Atlas, 1994

JOHNSON, H. Thomas; KAPLAN, Robert S.. A relevância da contabilidade de custos. Rio de Janeiro: Campus, 1996. 
KAPLAN, Robert S.; NORTON, David, P.. A estratégia em ação: Balanced Scorecard. Rio de Janeiro: Campus, 1997.

LEV, Baruch. Measuring the value of Intellectual Capital. Ivey Business Journal. New York, march/april, p. 16-20, 2001.

Remarks on the measurement, valuation and reporting odd intangible assets. Economic Policy Review, p. 17-22, september, 2003.

Sharpening the intangibles edge. Harvard Business Review (HBR) Spotlight, p. 109-116, June, 2004.

MARTIN, Nilton Cano. Da Contabilidade à Controladoria: a evolução necessária. Revista Contabilidade \& Finanças da FEA/ USP, São Paulo, n.28, p.7-27, jan./abr. 2002.

MELHORES \& Maiores. Revista Exame, julho 2003.

MOURITSEN, J.; BUKH, P.N.; LARSEN, H.T.; JOHANSEN, M.R. Developing and managing knowledge through intellectual capital statements. Journal of Intellectual Capital, Denmark, v. 3, n. 1, p. 10-29, 2002.

NAKAGAWA, Masayuki. Introdução à controladoria. São Paulo: Atlas, 1993.

PABLOS, Patricia Ordóñez. Evidence of intellectual capital measurement from Asia, Europe and Middle East. Journal of Intellectual Capital, Denmark, v. 3, n. 3, p. 287-302, 2002.

PELEIAS, Ivan Ricardo. Controladoria. São Paulo: Saraiva, 2002.

PEREIRA, Carlos Alberto. Avaliação de resultados e desempenhos. In: CATELLI, Armando (Org.). Controladoria: uma abordagem da gestão econômica. São Paulo: Atlas, 1999.
QUINN, James Brian. Intelligent enterprise. New York: The Free Pres, 1992.

ROOS, J.; ROOS, G.; EDVINSSON, Leif; DRAGONETTI, N. C.. Intellectual Capital: navigating in the new business landscape. London: Macmillan, 1997.

ROOS, G.; BAINBRIDGE, A.; JACOBSEN, K.. Intellectual capital analysis as a strategic tool. Strategy \& Leadership, v. 29, n. 4, p. 21-26, 2001.

STEWART, Thomas A.. Capital Intelectual: a nova vantagem competitiva das empresas. Rio de Janeiro: Campus, 1998.

The wealth of knowledge: intellectual capital and twenty-first century organization. New York: Currency Book, 2001

Your company's most valuable asset: Intellectual Capital. Fortune, p.28-33, Oct 3,1994.

SILVA, Auta Maria da. Fatores relevantes na implantação de um sistema de gestão (Enterprise Resource Planning (ERP) na área administrativa em uma Instituição de Ensino Superior. 2005. Dissertação (Mestrado Profissional em Administração) - Centro Universitário Nove de Julho, São Paulo.

SVEIBY, Karl Erik. A nova riqueza das organizações. Rio de Janeiro: Campus, 1998.

WU, Frederick H. Accounting information systems: theory and practice. New York: McGraw-Hill, 1983.

\section{Endereço da autora:}

Universidade Presbiteriana Mackenzie - SP

Rua da Consolação, 930 - Consolação

São Paulo - SP

01302-907 